\title{
Machado de Assis: o cronista e a construção da metrópole textual
}

Níncia Cecília Ribas Borges Teixeira | Unicentro

\begin{abstract}
"E tu, cidade minha, airosa e grata, Que ufana miras o faceiro gesto. Nessas águas tranqüilas, namorada. De remotos, magníficos destinos."

Machado de Assis
\end{abstract}

Resumo: A pesquisa pondera as relaçôes entre literatura e experiência urbana; sob essa perspectiva faz-se o levantamento das representaçôes da cidade do Rio de Janeiro, recém-inserida na modernidade e que ainda comporta vestígios do passado colonial. O trabalho tem como objeto central a análise das crônicas produzidas por Machado de Assis, escritor que pode ser considerado retratista de um Rio que se modernizava. O estudo dessas crônicas considera, além do enfoque literário, a configuração histórica e o forte apelo jornalistico desse gênero, que, até pouco tempo, era desconsiderado pelo cânone literário.

Palavras-chave: crônica; modernidade; Machado de Assis

A crônica machadiana e a reconstrução da cidade

passeio pelas imagens do Rio de Janeiro do século XIX e início do século XX, registrado pelo olhar dos escritores, levará à reconstrução literária da cidade. Há que se destacar a profunda heterogeneidade do campo intelectual do 
Rio de Janeiro, em função do entrecruzamento de várias experiências e influências culturais. A História dos primórdios da República é indissociável da História da cidade, que exerce influência significativa sobre o mundo das artes, e em especial da Literatura.

Com a implantação do projeto urbanístico de Pereira Passos (19021906), o Rio de Janeiro foi o palco primordial da encenação cultural da elite europeizada. Os paradigmas urbanísticos de circulação, higienização e ventilação determinavam uma nova reordenação topográfica. A abertura de amplas avenidas, o bota-abaixo do casario colonial, a crescente separação entre os redutos dos ricos e as zonas periféricas dos pobres estipulavam as ordenações da capital republicana, calcada na modernização do espaço público e no ideal de uma urbanidade cosmopolita. Entre a idealidade da cidade projetada e sua vivência, jazia o interstício interpretado, as entrelinhas de uma possível ação crítica.

A implantação do projeto urbanístico de Pereira Passos acabou dando origem a uma dualidade de ordens e valores que iria marcar decisivamente a tradição cultural da cidade. Enquanto Capital Federal, o Rio de Janeiro deveria transformar-se numa "Europa possível" e, ao mesmo tempo, corporificar um modelo de nacionalidade.

No âmbito da cidade simbólica, permeando a construção imagística da cidade progressista da Belle Époque, despontavam as críticas dissidentes. $\mathrm{Na}$ mestria irônica de Machado de Assis, a cidade, harmônica e ideal do planejamento burguês, é retratada como cenário de tensões sociais, trocas culturais e disputas.

Ao se reconstruir as imagens do Rio de Janeiro antigo, busca-se a reflexão em busca da legibilidade da cidade, por meio da representação que Machado de Assis faz dela em suas crônicas. Dotado de um olhar individualizado, esse escritor, escolhido como representante de um momento especialmente demarcado no percurso da modernidade, ensina que o conceito de cidade é um espaço movente e heterogêneo, no qual tempos e lugares se misturam em cruzamento de signos.

Machado de Assis foi um observador atento da cidade do Rio de Janeiro, utilizou-se do espaço literário para refletir sobre os acontecimentos da história urbana do Rio de Janeiro; sendo assim, portou-se como um retratista da sociedade carioca na segunda metade do século XIX. Machado inventa o mundo a partir do Rio de Janeiro; por meio de suas obras pode-se conhecer muito da história e das relações sociais do Brasil no fim do século XIX e início do XX.

A obra machadiana movimenta-se num espaço urbano de ação contemporânea, de onde emerge a visão do Brasil dos oitocentos, um espaço que abria as fronteiras para novas possibilidades, um Rio de Janeiro em via de se transformar na metrópole dos trópicos. Para Luzia de Maria, as obras de Machado de Assis 
revelarão "[c]ostumes e hábitos, a moda, as crenças, as relações de ordem social, ou mesmo as relações familiares no conjunto das normas burguesas, a posição da mulher e tudo que havia de hipócrita na sociedade".

Machado projeta a cidade como parte integrante de sua obra, por ela ser o habitat natural do homem civilizado. Pode-se dizer que as relações urbanas não aparecem propriamente dissecadas nas obras machadianas, antes, estão diluídas nos outros conflitos do texto - amorosos, políticos, morais - associadas à maioria das ações das personagens. Assim Bastide escreveu em seu artigo "Machado de Assis, paisagista":

[...] reputo Machado de Assis um dos maiores paisagistas brasileiros, um dos que deram à arte da paisagem na literatura um impulso semelhante, ao que se efetuou paralelamente na pintura, e que qualificarei, se me for permitido usar uma expressão "mallarmeneana" de presença, mas presença quase alucinante de uma ausência. ${ }^{2}$

No Brasil, as elites, desde a independência, inculcaram ao país modelos culturais europeus que podem ser descritos como cosmopolitas. Segundo o conceito tradicional, o cosmopolita é um homem aberto, tolerante, mundano e aberto à modernidade. Dessa forma, não surpreende que Joaquim Nabuco (1974), afirmasse ser a historia européia a sua história, e que a paisagem européia era a sua paisagem, e afirmava ser um espectador mais de seu século do que de seu país. Para ele a peça é a civilização, e estava sendo representada em todos os teatros da humanidade, ligada pelo telégrafo.

Dessa maneira singular, ele reforça o topos, onde se converte o mundo numa nação, de identidade cosmopolita e os estrangeiros, nos sócios dessa comunidade solidária e imaginada descrita por Anderson. A matriz francófila - tendo Paris como fulcro - foi descrita por Muniz Sodré como a base de onde "[...] nutriramse os sonhos, a consciência, os projetos criadores das elites brasileiras, pelo menos até serem trocados décadas mais tarde pela substância do imaginário norte-americano". ${ }^{3}$

Mas para que Paris chegasse, e reterritorializasse o Rio de Janeiro, era necessário empreender uma guerra contra a cidade e seu povo. Esse conflito ocorreu no contexto de consolidação da República, quando as elites no poder

1. MARIA, 1986, p. 36.

2. BASTIDE, 1940 , p. 1.

3. SODRÉ, 1988, p. 45. 
estigmatizaram as culturas populares, que envergonhavam o país aos olhos do mundo civilizado.

O projeto modernizador, imposto pelo governo federal ao Rio de Janeiro, atacava a questão do saneamento e determinava uma grande encomenda de obras públicas e respectivos equipamentos. Reproduzia-se, assim, de forma periférica, as portentosas obras de Paris. Seu impacto no imaginário da cidade pode ser aquilatado pelo conto Dias de fantasia no qual João do Rio conta as aventuras de um príncipe egípcio que, desembarcando no Rio de Janeiro, disse ter circulado por "ruas que me pareciam novas em folha, colocadas entre velhas vielas. [...] Não demorou muito para que meus olhos dessem com um boulevard iluminado como para uma festa. Era a Avenida Central". ${ }^{4}$

O Rio passa a ser um organismo vivo, palpitante, mas, na visão de Machado de Assis, já se configuram os inícios da lei da selva. A cidade é o palco das paixões, das intrigas, dos amores e das decepções das pessoas que ali habitam. Com certeza, não mais existe aquela empatia que unia a personagem à paisagem, concebida como um halo da natureza, pelos românticos. Pelo contrário, a cidade passa a ser o espaço de análise, por excelência, de processos políticos, sociais e culturais.

Sobre isso Brito Broca dirá:

Se lhe interessava, acima de tudo, a alma dos personagens, reconhecia que ela estava ligada a uma estrutura material e não podia agitar-se no espaço sem uma base física. A presença do Rio, com seus usos e costume, suas ruas e praças, seus bairros e praias, seus sobradões coloniais, suas andorinhas e cabriolés, constituía em sua obra o limite e ao mesmo tempo, a amplitude do Realismo psicológico em que ela se molda.

O olhar machadiano recai sobre os tipos e hábitos sócio-culturais de uma metrópole em desenvolvimento. Não se deve considerar apenas a observação da realidade urbana voltada para uma simples narrativa de costumes, mas também a observação de aspectos do homem e da sociedade.

A literatura, em especial as crônicas, foi particularmente sensível a essas mudanças, que atuaram diretamente sobre o modus faciendi do autor, fazendo emergir uma nova maneira de encarar a realidade circundante e refleti-la nas páginas

4. RIO, 1912, p. 51.

5. BROCA, 1958, p. 207. 
dos livros, e, em especial, dos periódicos, tornando a escrita mais ágil, mais eletrizante e febril, pois as temáticas incorporam a nova realidade do progresso técnico.

A crônica, gênero literário com forma e conteúdo comprometidos com aspectos do cotidiano, mostra-se fundamental no estabelecimento da relação entre ficção e história, principalmente quando nos referimos às últimas décadas do século XIX no Rio de Janeiro. Neste período, o gênero alcançou grande público e envolveu muitos literatos em sua elaboração, entre eles Machado de Assis. As crônicas cariocas da Belle époque, que foi o gênero literário que se impôs nesse período no Rio de Janeiro e teve como veículo de difusão os jornais - discutem a relação entre o progresso e a tradição, em que o primeiro - e com ele a transformação urbana - é entendido como inexorável, ao passo que o conceito de tradição se relaciona com um alerta à consciência nacional para a preservação dos monumentos do passado da memória e do patrimônio cultural da cidade.

Num Rio de Janeiro cheio de contrastes, Machado de Assis, por meio de suas crônicas, analisa a realidade urbana. Faz indagações do dia-a-dia, reflete o Rio de Janeiro, utilizando-se de um estilo sóbrio, reduzido ao essencial; enfim, disseca o mundo. A crônica de Machado é arte literária, sendo matriz de um conjunto de cronistas que deram relevo ao gênero durante todo o século XX, entre eles Mário de Andrade, Rubem Braga, Drummond, Clarice Lispector.

O texto de Machado de Assis, em suas crônicas, segundo Facioli:

[...] ganha relevo e sentido enquanto prática social e permite sua decifração fundada numa ironia estratégica, na qual falam muitas vozes, todas mediadoras da "verdade" do escritor, que se utiliza delas de múltiplas formas, sem que a opinião de Machado de Assis se imponha autoritariamente. Essas vozes são criadas e encenadas como opiniões sociais sem que seja portadora de verdade positiva. ${ }^{6}$

Em sua última entrevista, Carlos Drummond de Andrade enfatiza que, devido à sua natureza "fugitiva e fugidia", a crônica passa depressa. O autor alerta que, não obstante, deve-se reconhecer que:

As crônicas escritas há mais de cem anos, por um cidadão chamado Machado de Assis, estão hoje vivas como naquele tempo. Os acontecimentos perderam a atualidade, mas a crônica não perdeu, porque

6. FACIOLI, 1982, p. 82. 
ela traduz uma visão tão sutil, tão maliciosa, tão viva da realidade, que o acontecimento fica valendo pela interpretação que Machado de Assis deu. $^{7}$

Confirmam-se as palavras de Drumonnd, por meio deste fragmento de uma crônica de 6/9/1892, da série A Semana. Nesta crônica, Machado adverte que: "[...] o livro da semana dou um obituário, e não terás lido outra cousa, fora daqui senão mortes e mais mortes". 8 O tema a morte e a narrativa se estendem pela apresentação dos nomes das pessoas que partiram naquela semana.

No entanto, apesar de estes nomes perderem a atualidade, a introdução do texto é interessante devido à alusão do autor à morte com prazo determinado:

Qualquer de nós teria organizado este mundo melhor do que saiu. A morte, por exemplo, bem podia ser tão-somente a aposentadoria da vida, com prazo certo. Ninguém iria por moléstia, mas por natural invalidez; a velhice, tornando a pessoa incapaz, não a poria a cargo dos seus ou dos outros. Como isto, andaria assim desde o principio das cousas, ninguém sentiria dor nem temor, nem os que fossem, nem os que ficassem. Podia ser uma cerimônia doméstica ou pública; entraria nos costumes uma refeição de despedida, frugal, triste, em que os que iam morrer dissessem as saudades que levavam, fizessem recomendações, dessem conselhos, e se fossem alegres.

Essas linhas apresentam um encanto que permanece através dos tempos, pois as conjeturas presentes no texto levam o leitor à reflexão sobre a fugacidade da vida, tema que não perde a atualidade em nenhuma época da "comédia humana". Além disso, a morte geralmente é retratada como algo doloroso e traumático, aspecto que o escritor procura relativizar com a sugestão da morte não apenas como perda, mas, devido à previsibilidade, como algo programado e, de tal forma, isento de surpresas.

Nota-se, portanto, que Machado de Assis, apesar de ter como prérequisito o comentário dos fatos semanais, investe suas impressões sobre esses fatos de uma literariedade mais expressiva, à medida que o fato fica em segundo plano e o que prevalece é a interpretação.

7. ANDRADE, 1999, p. 13.

8. MACHADO DE ASSIS, 1994, p. 51.

9. MACHADO DE ASSIS, 1985, p. 49-51. 
Deve-se considerar, também, o registro cronístico de aspectos relevantes do cotidiano do Rio de Janeiro, por meio de comentários, aparentemente banais, sobre determinada situação, com injeção de elementos ficcionais, numa fusão entre reportagem de jornal e conto. Para Pesavento, "Machado resgata uma sensibilidade da vida urbana de sua época, recolhendo aquele viés da cidade moderna em transformação". ${ }^{10}$ Essa afirmação pode ser constatada em crônica de 4/5/1893:

Houve sol, e grande sol, naquele domingo de 1888, em que o Senado votou a lei, que a regente sancionou, e todos saímos à rua. Sim, também eu saí à rua, eu o mais encolhido dos caramujos, também eu entrei no préstito, em carruagem aberta, se me fazem favor, hóspede de um gordo amigo ausente; todos respiravam felicidade, tudo era delírio. Verdadeiramente, foi o único dia de delírio público que me lembro ter visto. Essas memórias atravessaram-me o espírito, enquanto os pássaros treinavam os nomes dos grandes batalhadores e vencedores, que receberam ontem nesta mesma coluna da Gazeta a merecida glorificação. No meio de tudo, porém, uma tristeza indefinível. A ausência do sol coincidia com a do povo? O espírito público tornaria à sanidade habitual? ${ }^{11}$

O que se pretende mostrar é que as crônicas de fato fazem parte de um projeto que visava a fundir literatura e história em uma obra que tivesse como contrapartida a fusão entre ficção e realidade. Nas palavras de Arrigucci Jr, "Essas crônicas são um elo valioso das relações entre ficção e história e, como tal, não visavam à compreensão dos fatos que permeiam a transmutação de ambas." ${ }^{12}$ Em 11 de novembro de 1897, o autor escreve em sua página semanal na Gazeta de Notícias:

Eu gosto de catar o mínimo e o escondido. Onde ninguém mete o nariz, aí entra o meu com a curiosidade estreita e aguda que descobre o encoberto. Daí vem que, enquanto o telégrafo nos dava notícia tão graves, como a taxa francesa sobre a falta de filhos e o suicídio do chefe de polícia paraguaio, cousas que entram pelos olhos, eu apertei os meus para ver cousas miúdas, cousas que escapam ao maior número, cousas de míopes. A vantagem dos míopes é enxergar onde as grandes vistas não pegam. ${ }^{13}$

10. PESAVENTO, 2002, p. 12.

11. MACHADO DE ASSIS, 1985, p. 583.

12. ARRIGUCCI JR., 1987, p. 59.

13. MACHADO DE ASSIS, 1985, p. 772. 
Nesse ponto, Machado de Assis soube como poucos transformar o cotidiano em algo importante, indo além do simples fato, mostrando à coletividade, a história como nenhum historiador poderia fazê-lo. Nas crônicas machadianas, delineiam-se com clareza a apreensão do fato cotidiano, desimportante enquanto ação, mas explorado em seu conteúdo pitoresco, humano e urbano das relações do Rio de Janeiro do final do século XIX. Em crônica de 1877, Machado de Assis, na série História de 15 dias, comentou:

Mais dia, menos dia, demito-me deste lugar. Um historiador de quinzena, que passa os dias no fundo de um gabinete escuro e solitário, que não via às touradas, ás câmaras, à Rua do Ouvidor, um historiador assim e um puro contador de histórias. E repare o leitor como a língua portuguesa é engenhosa. Um contador de histórias é justamente o contrário de historiador, não sendo um historiador, afinal de contas, mais do que um contador de histórias. ${ }^{14}$

A matéria da escrita do cronista demonstra que são os acontecimentos cotidianos que marcam o tempo histórico da coletividade. O cronista passa a ser o "contador de histórias" transformando fatos históricos em ficção conferindo-lhes certa perenidade. Logo, o papel do cronista é bastante complexo, pois apesar de se ocupar de aspectos banais, ele deve, também, ser sério, gerando, dessa forma, uma dicotomia entre o que é aparente é o que está subentendido.

À moda do flâneur, Machado contempla elementos que fazem da, então Capital Federal, um espaço singular onde convivem as mais diferentes profissões, práticas religiosas, festas, vícios e virtudes, ligados, com certa freqüência, às camadas populares. As crônicas de Machado de Assis fundem história e ficção imagens do Rio de Janeiro do final do século XIX e início do século. XX. O escritor ao criar o narrador-flâneur procurará reconstruir a identidade urbana por meio dos discursos literários. O seu olhar percorrerá os caminhos do sensível e imaginário, revelando as imagens da sociedade, por vezes, não admitidas por esta ou que não são perceptíveis nas fontes históricas tradicionais.

Dessa feita, por meio das imagens urbanas e literárias que as crônicas machadianas revelam, em especial as crônicas de A Semana (1892-1897) é que se buscará a configuração do mapa histórico-discursivo do Rio no final do século XIX. Na série Semana, Machado de Assis projeta um Rio que se apresentava como

14. MACHADO DE ASSIS, 1985, p. 361. 
moderno, mas que ainda possuía traços de profundo elo com o passado colonial. O cronista, portanto, atento a todas as mudanças pelas quais a Capital Federal passava, funcionou com um sensor aguçado que soube captar a grande maré de mudanças provocada pela inserção do Rio de Janeiro no turbulento e amplo panorama da modernidade. Por outro lado, os textos de $A$ Semana conferem a eles uma certa ambigüidade, o que torna difícil afirmar qual é a sua posição real diante dos assuntos que comenta, nunca se tem certeza se o autor fala sério ou não. Assim, com freqüência, não se sabe com quem se esta dialogando, se com o narrador ou com o enunciador do texto. Vale salientar, também, que raramente o Rio de Janeiro irá ser analisado de forma unívoca, mas sempre ambivalente, com certa relatividade. Percebe-se que o autor se vale de um material não literário, mas o transforma, ao projetar seu olhar sobre a sociedade.

\section{Imagens machadianas do Rio de Janeiro}

O Rio de Janeiro, a metrópole cultural, seus habitantes, lojas, cafés, confeitarias e subúrbios estão obviamente configurados na literatura do final do século XIX e início do século XX. É o Rio antigo, um Rio que desapareceu, um Rio que virou lembrança e que pode ser reconstruído através das páginas literárias.

Era, porém, necessária a construção, ou a invenção da metrópole que se baseia na idéia de que era necessário anular a visão provinciana da cidade do Rio de Janeiro, garantindo a imposição de hábitos e costumes, padrões de comportamento e de linguagem, gosto e moda, numa clara intenção unificadora e homogeneizadora. Aos modos de agir, pensar e sentir da "província", a capital teria que contrapor padrões e normas que deveriam ser internalizados por todos aqueles desejosos de se tornar homens da corte.

A construção da capitalidade do Rio de Janeiro tinha ainda um outro pilar: o cosmopolitismo. A cidade era o principal elo de ligação com o mundo europeu, e se tornando a fonte de irradiação dessa civilização no país. Pode-se creditar, em larga medida, ao potencial mercantil do Rio de Janeiro, que só fez crescer, após a independência, o lugar preeminente que essa cidade ocupou na economia imperial.

Como cidade-capital, o Rio de Janeiro deveria ser o baluarte da unidade e da centralização, o que significava enfrentar o desafio de unificar uma vasta região pontuada por ilhas econômicas e culturais, desejosas de emancipação

política, suprema ameaça. Competia-lhe dominar e civilizar o seu entorno, marcando 
a fronteira da barbárie, encarnada tanto nas ameaçadoras revoltas das províncias, quanto nos rudes costumes do seu povo da capital.

A recuperação das imagens urbanas da cidade, por meio do olhar arguto de Machado de Assis, configura um importante registro da formação da moderna cidade do Rio de Janeiro no limiar do século XX, ao focalizar os costumes, práticas cotidianas, organização da ordem pública, relações familiares e outras tantas relações sociais. De um lado, é visível a presença dos avanços tecnológicos e do impacto por eles causados na cena carioca, de outro, é possível observar resquícios, que não se deixam encobrir, deixados pelo passado colonial.

\section{E o bonde chegou...}

O Rio de Janeiro, no final do século XIX, é envolto num clima de um cosmopolitismo ascendente, moldado nas imagens advindas do modelo europeu, em especial o parisiense, que remete ao ritmo alucinante do progresso industrial, mecânico, político e social. O impacto dessa tecnologia causará mudanças significativas na vida social e cultural, que vai exercer seu domínio sobre a imaginação da sociedade brasileira. Para Park, "[o] transporte e a comunicação efetuaram, entre muitas outras, mudanças silenciosas, mas penetrantes". ${ }^{15}$

Ao se ler as folhas finisseculares de Machado de Assis, depara-se com os movimentos significativos do Rio de Janeiro em sua passagem para a modernidade. Esta passagem se converte em meio de transporte, para a análise de diversos processos sociais, históricos, políticos e econômicos, que se desencadeiam até hoje.

Ao meter o seu nariz no futuro, em sua "curiosidade estreita e aguda", Machado lança um seu olhar confessando "catar o mínimo escondido". Sua atenção, então, volta-se ao que se descarta, ao que se desterritorializa no processo vertiginoso da modernidade. Essse movimento desterritorializador da mecanização é registrado nas crônicas de Machado de Assis, identificando-se especificamente ao movimento dos bondes no Rio de Janeiro. Recuperar os passos desse movimento, significa

15. PARK, 1967 , p. 67. 
reler uma série de crônicas em que são registradas essas passagens. É pelo divagar do cronista, que se vai construindo uma metrópole multifacetada, devido à multiplicidade de pontos de vista de Machado de Assis cronista, que se confundem, muitas vezes, com a voz de seus narradores.

As crônicas machadianas carregam o leitor por um ritmo de velocidade ,desde os bondes movidos por burros, à sua nova forma vertiginosa e autônoma, por trilhos elétricos. Essa nova coletividade eletrizante do bonde não só desperta o passageiro para um mundo individual, mas provoca questões de fronteiras antes demarcadas, como as de hábitos privados que se fazem públicos.

Lançando mão do conjunto de elementos presentes nessas crônicas, é que se pretende traçar o mapa discursivo-literário da cidade do Rio de Janeiro. As narrativas machadianas possuem uma composição que articulam vários planos, tais como o do conteúdo histórico e o da narrativa ficcional, a partir dos quais se pode inventar, problematizar e discutir questões incentivando a participação do leitor. Essa participação é efetivada pela desarticulação do real, que possibilita o estabelecimento de uma reflexão da história pela representação literária.

As crônicas escritas por Machado de Assis configuram uma dialogia, um território compartilhado pela linguagem e pelo discurso, em que se cria o espaço para a manifestação ideológica, essa atitude que se torna implícita, é o que caracteriza seus narradores.

Esta crônica, veiculada em 16/10/1892, anuncia a inauguração dos bondes elétricos:

Não tendo assistido a inauguração dos bonds elétricos, deixei de falar neles. Nem sequer entrei em algum, mais tarde, para receber as impressões da nova tração e contá-las. Daí o meu silêncio da outra semana. Anteontem, porém, indo pela Praia da Lapa, em um bond comum, encontrei um dos elétricos, que descia. Era o primeiro que estes meus olhos viam andar. Para não mentir, direi o que me impressionou, antes da eletricidade, foi o gesto do cocheiro. Os olhos do homem passavam por cima da gente que ia no meu bond, com um grande ar de superioridade. Posto não fosse feio, não eram as prendas físicas que lhe davam aquele aspecto. ${ }^{16}$

A partir do caso pessoal observado, o cronista comenta sobre o suposto progresso, representado pelos bondes e figurado no orgulho do motorneiro. Não

16. MACHADO DE ASSIS, 1985 , p. 550 . 
se trata de um assunto comum, imperceptível sob a capa do cotidiano. Ao contrário, o fato novo vem alterar a rotina da população. A perspectiva adotada, no entanto, parte de um ângulo inesperado, aparentemente mínimo, em que se focaliza o gesto do cocheiro, seu ar de superioridade. Nele, o cronista encontra a glória de empréstimo, em que o homem comum sente-se grande por estar conduzindo o novo veículo, por ser o centro das atenções, por se sentir o condutor da própria modernidade, de encarnar a eletricidade.

O que se nota, nesse texto, é que o cronista continua a ser o narrador, por excelência, de um Rio de Janeiro às voltas com a modernização; no entanto torna-se um contador de casos, aquele que transforma a história da coletividade em ficção, conferindo-lhe a recuperação do seu adversário: o tempo. Ao utilizar a metáfora "bonde", o autor reforça a mecanização, marca da modernidade.

$O$ ato de narrar de Machado demonstra, antes de informar acerca de algum acontecimento, uma forma de compreender o mundo. Nesse ponto ocorre, ao menos em tese, a grande diferença em relação à crônica jornalística, ou seja, os acontecimentos são reconstituídos durante a narrativa e, dessa forma, subordinamse a ela.

Quando anuncia a inauguração dos bondes elétricos, o narrador, como de hábito, cita os acontecimentos marcantes da semana, mas o faz introduzindo-os no contexto de elaboração da crônica, de forma que o que é narrado, não são exatamente os acontecimentos mais marcantes, mas o seu processo de contar. Os fatos comentados deixam de ser notícias e passam a ser personagem do cronista e passam a ser os desencadeadores do discurso que está por vir. Assim, ao ir além da "pobre ocorrência", mostra ao homem a história, especificamente a história de um Rio de Janeiro que se moderniza.

O bonde também torna visível a cidade, até então, mal entrevista nos deslocamentos dos habitantes pelos antigos meios de transportes, quase sempre fechados, e estabelece, em seus bancos, a convivência democrática (embora pouco tolerada) dos cidadãos fluminenses. Essa convivência, que gera certa miscigenação social, encontrará alguma resistência no início, mas, ao fim de algum tempo, todos mergulharão na efervescência do novo ritmo de civilização.

A crônica abaixo foi redigida por Machado de Assis na série Balas de Estalo, publicada em 4/7/1883, nela o autor escreve uma espécie de estatuto, que sistematiza normas para se viver incorporado ao padrão cosmopolita: 
Ocorreu-me compor umas certas regras para uso dos que freqüentam bonds. O desenvolvimento que tem sido entre nós esse meio de locomoção, essencialmente democrático, exige que ele não seja deixado ao puro capricho dos passageiros [...]

ART. II - Da posição das pernas

As pernas devem trazer-se de modo que não constranjam os passageiros do mesmo banco. Não se proíbem formalmente as pernas abertas, mas com a condição de pagar os outros lugares, e fazê-los ocupar por meninas pobres ou viúvas desvalidas, mediante uma pequena gratificação.

ART. III - Da leitura dos jornais

Cada vez que um passageiro abrir a folha que estiver lendo, terá o cuidado de não roçar as ventas dos vizinhos, nem levar-lhes os chapéus. Também não é bonito encostá-los no passageiro da frente. [...]

$A R T$. IX - Da passagem às senhoras

Quando alguma senhora entrar o passageiro da ponta deve levantar-se e dar passagem, não só porque é incômodo para ele ficar sentado, apertando as pernas, como porque é uma grande má-criação.

$[\ldots]^{17}$

Num tom irônico e bem humorado, o narrador dá indicações, nas entrelinhas, sobre as novas posturas que uma sociedade refinada deve ter, para se ajustar ao panorama gerado pela modernização, aqui representada, novamente, pelo advento trilho urbano. O cronista vê no bonde um espaço que possibilita a universalização e o nivelamento de oportunidades. Portando-se como um narradordândi, que carrega consigo uma atitude totalmente adaptada à rapidez das mudanças na vida metropolitana, ele tenta sistematizar a conduta do carioca refinado.

Nota-se que, nessa crônica, o narrador utiliza-se do espaço da narrativa para ensinar; servindo-se do estereótipo do dândi, ele insinua que é necessário ter modelos para conviver em meio à civilização moderna. Assim, de forma irônica, mostra-se como um dândi "às avessas", pois insinua uma imitação vazia, já que tudo isso soa falso e iguala-se a um jogo, deixando para trás uma realidade séria (a

17. MACHADO DE ASSIS, 1985, p. 415. 
imitação de hábitos). Dândi "às avessas", porque segundo Benjamim, "O dandy brinda o ócio e o prazer no cortejo do virtual e do inútil, o dandy opta por distinguirse pela sua indumentária, há uma certa teatralidade em suas atitudes" . ${ }^{18}$ Em nenhum momento, ele desmancha o cenário em busca de reflexões, e este narrador parece agir como um dândi; no entanto, ele expressa uma crítica contundente sobre essa imitação vazia. Novamente, tem-se o posicionamento do narrador-cronista, que pode ser captado pelo avesso do texto.

Com a chegada dos bondes, ocorreram mudanças nos costumes da cidade; o aparecimento desses fará existir duas cidades: a do arrabalde e a do centro, indo até Botafogo. A divisão da cidade, em duas categorias específicas, resulta da maneira como cada habitante faz uso dela. Nessa nova cidade, que corresponde também a um mundo em decadência, de uma cultura derradeira e mortalmente ferida pelo fetiche da mercadoria e pelo capitalismo burguês, os seus passeios amplos convidavam agora à circulação e essa atividade (a flânerie) constituirá a ocupação privilegiada do burguês ocioso (o flâneur), aquele que sustenta a convicção da fecundidade da flânerie, de que fala, não apenas Benjamin, nos seus estudos sobre Baudelaire, como também o próprio Baudelaire, na sua obra As flores do mal. Tudo conseqüência, evidentemente, da nova paisagem física e do surgimento de bairros prestigiados, por onde passam os elegantes, os flâneurs, os dândis, enfim o homem das multidões, na acepção benjaminiana.

O advento do trilho urbano foi o responsável pelo contato forçado e desagradável - para a elite carioca - entre dois mundos que se supunham separados. Um Rio que se esbarra nas ruas, que compara suas diferenças e se choca com a coabitação, no mesmo espaço, de indivíduos de extração social tão diversa. Isso será revelado pelas tensões sociais existentes entre o novo e o antigo, que se firmam num processo de negação da identidade colonial.

As posições entre o progresso e a tradição se traduzem numa associação da cidade colonial ao popular, e as manifestações de cultura desta classe e suas sociabilidades são sinônimos de atraso. O novo deveria estar ligado ao mito parisiense, modelo paradigmático de cidade moderna.

Machado de Assis, ao embarcar no bonde da história, utiliza-se da ambivalência ficção-fato, para demonstrar os mais variados pontos de vista acerca da chegada da modernidade. Observa-se que o ritmo veloz da modernidade será

18. BENJAMIN, 1991, p. 54 
registrado alegoricamente pelo movimento dos bondes, que entrou arrastando o país para uma nova era.

As crônicas de Machado traduzem tanto uma representação do urbano que revelam a sedução pelo progresso, quanto uma leitura metaforizada do processo de modernização. O binômio progresso-tradição não se apresenta como excludente e sim acontece de forma combinada, num cenário em que havia uma exacerbação da tendência progressista, que se configurava como aspecto central para a definição do novo padrão de identidade da nação. O autor consegue olhar, como se fosse de fora, para a realidade nacional, ele capta os contrastes da cidade no momento em que ela se fortalecia como metrópole.

As crônicas de A Semana fazem parte de um projeto que funde literatura e história em uma obra única, que tem como contrapartida a fusão entre ficção e realidade.Conforme Arrigucci Jr: "Essas crônicas são um elo valioso das relações entre ficção e história e, como tal, não visaram à identificação de uma ou de outra parte que unia, mas à compreensão dos fatos que permeiam a transmutação de ambas" .

Abstract: This study ponders the relations between literature and urban experience. In this perspective the representations of the city of Rio de Janeiro, recently inserted in modernity and still having traces of its colonial past, are mapped. The study has as its main objective to analyse chronicles produced by Machado de Assis, a writer that can be considered a "portrayer" of the modernizing Rio. The study of such chronicles considers, besides the literary focus, the historical configuration and the strong journalistic appeal of such genre, which has been disregarded by the literary canon.

Keywords: chronicle; modernity; Machado de Assis

19. ARRIGUCCI JR., 1987, p. 59. 


$$
\text { Referências }
$$

ANDRADE, Carlos Drummond de. Uma prosa inédita com Carlos Drummond de Andrade. Caros Amigos, São Paulo, n. 29, p.12-15, ago/1999. Entrevista.

ARRIGUCCI JR., Davi. Enigma e comentário. São Paulo: Companhia das Letras, 1987.

BASTIDE, R. Machado de Assis paisagista. Revista do Brasil. Rio de Janeiro, n. 29, p. $45-48,1940$.

BENJAMIN, Walter. Obras Escolbidas III: Charles Baudelaire, um lírico no auge do capitalismo. São Paulo: Brasiliense, 1991

BROCA, Brito. A vida literária no Brasil-1900. Rio de Janeiro: MEC, 1958.

FACIOLI, Valentim. A crônica. In: BOSI, Alfredo et al. (Org.). Machado de Assis. São Paulo: Ática, 1982. p. 86-87.

FACIOLI, Valentim. Várias histórias para um homem célebre: biografia intelectual. In: BOSI, Alfredo et al. (Org.). Machado de Assis. São Paulo: Ática, 1982. p. 9-53.

MACHADO DE ASSIS, Joaquim Maria. Obra completa. Org. Afrânio Coutinho. 2. ed. Rio de Janeiro: Ed. Nova Aguilar, 1985. v. 3.

MACHADO DE ASSIS, Joaquim Maria. Crônicas escolhidas. Sel. e introd. de Fernando Paixão. São Paulo: Ática, 1994.

MARIA, Luzia de. Machado de Assis: as artimanhas do humano. São Paulo: Brasiliense, 1986.

NABUCO, Joaquim. Minha formação. São Paulo: Três, 1974.

PARK, Robert Ezra. A cidade: sugestões para a investigação do comportamento humano no meio urbano. In: VELHO, Otávio Guilherme (Org.). O fenômeno urbano. 2. ed. Rio de Janeiro: Zahar, 1967. p. 60-67.

PESAVENTO, Sandra J. O imaginário da cidade: visões literárias do urbano. 2. ed. Porto Alegre: UFRG, 2002.

PESAVENTO, Sandra J.; LEENHARDT, Jacques (Org.). Discurso histórico e narrativa literária. Campinas: Unicamp, 1998.

RIO, João do. Os dias passam. Porto: Chaudron, 1912.

SODRÉ, Muniz, O terreiro e a cidade: a forma social negro-brasileira. Petrópolis: Vozes, 1988. 